\title{
Cultura policial e adolescente suspeito - a normalização na Gerência de Polícia em Recife
}

\author{
Érica Babini Lapa do Amaral Machado \\ Doutora em Direito pela UFPE \\ Professora da Universidade Católica do Pernambuco \\ ericababini@hotmail.com \\ Murilo Sobral Neto \\ Mestrando em Direito pela Universidade Católica do Pernambuco \\ Iana Lira Pires \\ Graduada em Direito pela Universidade Católica do Pernambuco
}

\begin{abstract}
Resumo Este trabalho discute representações sociais das polícias no momento da lavratura do auto de prisão em flagrante de adolescentes em conflito com a lei. O produto foi obtido por observação etnográfica, a partir da problematização levantada por marcos teóricos da criminologia crítica e da sociologia criminal, em que se teve como hipótese a ideia de que, se a criminalização é um processo de rotulação e se as polícias, em geral, são instituições desacreditadas jurídica e socialmente, mas que delas a população demanda segurança pública, outra conclusão não poderia ser extraída senão a de que os agentes dessas instituições não respeitam a legalidade e atuam de maneira arbitrária, no sentido de executar os padrões de normalidade que a sociedade estabelece e, consequentemente, reafirmar sua importância social. Neste sentido, estaria orientada a construção social do adolescente suspeito.
\end{abstract}

Palavras-chave: Polícias, adolescente em conflito com a lei, suspeito e normalização.

\section{Introdução}

E ste trabalho pretendeu compreender, à luz do marco interpretati- vo da sociologia criminal e da criminologia crítica, a atuação dos agentes policiais no momento da lavratura do flagrante de adolescentes que praticam um ilícito penal.

A problemática tem como perspectiva que a polícia, como agência oficial de controle social, reproduz demandas e valores da sociedade (Baratta, 2002); porém, estando extremamente desacreditada perante o Judiciário e a população, precisa demonstrar que sua atividade é indispensável (Kant de Lima, 2004). Neste sentido, a hipótese é a de que a polícia precisa reafirmar para o observador (a sociedade e o Judiciário) que seu trabalho é útil e necessário; assim, precisa confirmar que o adolescente apreendido em situação de flagrante é necessariamente infrator, pois, do contrário, seu trabalho não faria sentido. Com isso, a polícia não faria trabalho de investigação do fato, mas sim uma confirmação do status do adolescente para que a instituição ratifique sua importância social. 
A hipótese de trabalho foi manejada por revisão bibliográfica e observação não participante, de viés etnográfico, realizada entre fevereiro e março de 2015, na Gerência de Polícia da Criança e do Adolescente da cidade do Recife, para onde são levados adolescentes apreendidos em flagrante.

O pressuposto deste trabalho é o de que a adolescência é uma época em que o indivíduo ganha maior notoriedade dentro do meio social, sendo reconhecido como um sujeito capaz de exercer seus direitos. Com esse reconhecimento, é atribuída a ele uma série de responsabilidades, dentre as quais a criminal, ainda que fundamentada em preceitos normativos distintos dos adultos.

Ainda que o tratamento - no âmbito legislativo - conferido aos menores de 18 anos seja distinto, o sistema criminal, a partir de uma atuação das suas agências revestida de legalidade, apropria-se dos conflitos envolvendo os adolescentes sem qualquer distinção, sujeitando-os às mesmas práticas político-criminais a que os penalmente imputáveis estão submetidos (Machado, 2014; Mallart, 2014).

Zaffaroni (2003) deixa isso evidente ao mencionar que, além do sistema penal em sentido estrito, existem outros paralelos, compostos por agências de menor hierarquia, destinadas a operar com menos punição, razão pela qual gozam de maior discricionariedade e arbitrariedade. Porém, tal qual o sistema punitivo, admitem técnicas (ilícitas) subterrâneas normalizadas em termos estatais, dado o fim que prometem cumprir.

Tal problemática deve ser compreendida por meio de um estudo crítico que enseje a desmitificação da atuação dessas agências sobre os indivíduos, adultos ou adolescentes, que estão sujeitos ao seu controle.

\section{Processo de criminalização: a cultura policial e sociedade do controle - um processo de retroalimentação}

O tratamento antagônico conferido pelas agências de controle aos adolescentes em conflito com a lei deve ser entendido à luz da criminologia crítica, cujas ideias estão fundamentadas no interacionismo simbólico, pois não seria possível repreender uma conduta que não causasse nenhuma comoção social negativa, a pretexto de que esta seria tida como incorreta. Explica Baratta (2002, p. 87): "Segundo o interacionismo simbólico, a sociedade é constituída por uma infinidade de interações concretas entre indivíduos, aos quais um processo de tipificação confere um significado (...)."

Ocorre que o comportamento que sofre uma repressão social representa uma série de reações, baseadas em valores presentes na sociedade, as quais rotulam como desviante, por uma interpretação, esse comportamento. Como afirma Baratta (2002, p. 95):

Pode-se facilmente compreender que, para desencadear a reação social, o comportamento deve ser capaz de perturbar a percepção habitual (...) ou seja, que suscita, entre as pessoas implicadas, indignação moral, embaraço, irritação, sentimento de culpa e outros sentimentos análogos.

Como consequência, muito antes da prática de qualquer conduta ilícita, recai sobre esses indivíduos a figura do outsider, com o que se provoca uma estigmatização do indivíduo, conferindo-lhe a entrada em uma carreira criminosa:

Quando uma regra é imposta, a pessoa que presumivelmente a infringiu pode ser vista como um tipo especial, alguém de quem não se espera viver de acordo com as regras estipuladas pelo grupo. Essa pessoa é encarada como um outsider. (Becker, 2003, p. 15)

Afinal, as agências oficiais de poder "acentuam o caráter seletivo do sistema penal abstrato" (Baratta, 2002, p. 176), sendo uma extensão formal da reação social. Desta forma, um sujeito que já vivia às margens do convívio social por não compartilhar os valores de uma sociedade conservadora, individualista e consumista, agora passa a ocupar uma cadeira cativa e permanente na marginalidade. ${ }^{1}$

Como resultado desse processo de criminalização, a criminalidade, ainda que presente em todos os estratos da sociedade, passa a ser vista como uma conduta extremamente perigosa pertencente a um único grupo social. Assim, o que influencia a ação das agências criminais não é a conduta por si só, mas as variáveis relativas à personalidade do autor.

As maiores chances de ser selecionado para fazer parte da "população criminosa" aparecem, de fato, concentradas nos níveis mais baixos da escala social (subproletariado e grupos marginais). A posição precária no mercado de trabalho (desocupados, subocupação, falta de qualificação profissional) e defeitos de socialização familiar e escolar, que são características dos indivíduos pertencentes aos níveis mais baixos, e que na criminologia positivista e em boa parte da criminologia liberal contemporânea são indicados como as

1. Esta expressão carrega consigo uma interpretação ambígua, que faz referência a quem está na margem social como alguém que está no mundo da criminalidade. 
causas da criminalidade, revelam ser, antes, conotações sobre a base das quais o status de criminoso é atribuído. (Baratta, 2002, p. 165).

Enfim, o fluxo do processo de rotulação (que depende do grau de reação social para imputação de um status) é guiado pela lógica da estereotipação, um conceito que permeia a forma de conhecimento - primeiro define-se, para depois ver-se o que é o mundo; um processo de caracterização que se realiza, na socialização, na ordenação de expectativas de comportamentos.

De acordo com Schur (1971, p. 51), "agências de controle refletem os estereótipos da opinião pública", enquanto as polícias - configurando uma instituição pertencente ao sistema de justiça criminal, tendo como atribuição precípua a garantia da segurança pública - são a primeira instituição a realizar o processo de criminalização. Elas são a porta de entrada do indivíduo no sistema de justiça criminal, e, por isso, são responsáveis por uma resposta imediata à reação social que as provocou. Não raras vezes a reação advinda desses órgãos excede o limite estabelecido pela lei penal, fazendo com que sejam alvo de críticas por utilizar, sobre determinados grupos, mecanismos excessivamente repressivos.

É preciso conhecer melhor o papel e a atuação cultural dessa instituição.

\section{Polícias, operatividade e busca da credibilidade}

A polícia não é uma, ${ }^{2}$ visto que a sua estrutura comporta órgãos que, visando preservar a ordem pública, atuam em esferas distintas, de modo a garantir uma maior eficiência ao serviço público prestado. Quando se trata de infrações penais, dentro da instituição policial as polícias militar e civil são os dois órgãos que se sobressaem, ainda que possuam funções claramente distintas.

É de se considerar que heranças culturais permanecem vivas e isso deve ser levado em consideração no estudo dos modelos de controle social. DaMatta (1982, p. 21), ao tratar da violência, discute a importância do estudo do objeto a partir da experiência local, na qual, mesmo havendo influências de modelos estrangeiros, é necessário a tradução para a realidade brasileira, uma sociedade cujo "dinamismo [...] permite que pessoas e grupos mudem radicalmente de posição, desde que se mude de assunto, de contexto ou de espaço social".

Quer aduzir o autor que o mundo social, em nosso país, é orientado por múltiplas esferas, cada qual contendo seu código social e sua própria ética, de modo que a casa, a rua e o outro mundo, como ele denomina, são eixos do jogo de poder e exploração nas esferas da vida, de onde emanam as raízes da violência no sistema social. Algo que o autor, em Você sabe com quem está falando?, exprimiu como uma reação violenta às leis universais que todos, de alguma maneira, manejam - seja na reação violenta (ou no berro) às relações verticais que se impõem, seja como uma estratégia pessoal de demarcação de poder.

Essa maneira de interpretar a realidade brasileira perpassa também a forma pela qual deve-se analisar a atuação das polícias, pois estas, além de inseridas nessas complexidades, submetem-se a um modelo ambíguo do sistema processual. Isso leva essa instituição a transacionar com representações hierarquizadas, presentes no pensamento social, produzindo e reproduzindo verdades (expectativas) - e com realização de segurança pública - a partir de um modelo de processo penal marcado pela cultura legal, abstrata e formal do Direito, em que os fatos submetem-se a um tratamento lógico-formal (Kant de Lima, 2004).

Em razão de uma gama de ambiguidades - sistema do inquérito policial inquisitivo (com ausência de controle do devido processo legal), ${ }^{3}$ função de vigilância e manutenção da ordem pública (que a impele a agir com suspeição sistemática, com base no comportamento virtual do indivíduo e com discricionariedade) e postura inferiorizada perante o Judiciário (suas provas precisam ser reproduzidas) -, a polícia "marca sua existência como permanente liminaridade" e leva o exercício da prevenção "com métodos inquisitoriais e a prisão com princípios de vigilância" (Kant de Lima, 2004, p. 6).

Por outro lado, a conjuntura policial é formatada a partir de uma lógica em que o órgão não é construído com o fim de administrar ou pacificar os conflitos, mas de extingui-los, punindo os sujeitos neles envolvidos (Kant de Lima, 2014). Esta reduzida - quase nula - capacidade de mediação e conciliação se dá por seu poder de negociação não ser legitimado diante das demais instâncias pertencentes ao controle social, tendo em vista seu caráter repressivo.

A função da polícia se caracteriza, assim, por ser eminentemente interpretativa, partindo não só dos fatos,

3. Os autores são absolutamente cientes da releitura constitucional do Código de Processo Penal (Jacinto Nelson de Miranda Coutinho, Eugenio Pacceli de Oliveira, Aury Lopes Junior, Geraldo Prado, Alexandre de Morais da Rosa indicam tal necessidade), porém, também estão cientes que as práticas cotidianas, até mesmo do Judiciário, ainda estão muito longe da orientação democrática. 
mas, principalmente, da decifração do lugar de cada uma das partes em conflito na estrutura social para proceder à correta aplicação das regras de tratamento desigual aos estruturalmente desiguais. (Kant de Lima, 1997, p. 83).

Como consequência deste tipo de função, há uma notória dificuldade das agências criminais, como um todo, para comportarem-se como sistemas - e, como tal, perseguirem as mesmas finalidades -, visto que a polícia, ao se organizar, de forma precípua, para reprimir as práticas lesivas aos bens jurídicos, acaba indo de encontro aos preceitos adotados pelo próprio Estado quando da resolução dos conflitos.

Tal qual ocorre com o sistema de justiça criminal, há um frequente questionamento acerca do desempenho falho dos agentes ser consequência de fatores que, se modificados, possibilitariam a adoção, pela instituição, de novas perspectivas compatíveis ao seu objetivo precípuo.

Adotar essa opção como a mais acertada para resolver os problemas advindos das práticas policiais seria fechar os olhos para as funções reais a serem desempenhadas pela polícia. Ao final, o que se pode observar é uma instituição com um visível potencial destruidor de ordem tentando, sem sucesso, garanti-la a todo custo e, assim como o próprio sistema de justiça criminal que lhe sustenta, sendo cada vez mais legitimada pela população para tanto.

Desse modo, tal qual o sistema criminal, a polícia se orienta por valores e ideologias diversas das que foram explicitamente informadas à sociedade, acabando por agir de forma truculenta e lesando bens jurídicos, ao invés de protegê-los.

O tratamento dirigido aos civis se dá porque o "tipo de formação institucional que os policiais militares e civis recebem é de caráter repressivo, dogmático e instrucional, seja porque ligado ao direito punitivo, seja porque inspirado na formação militar" (Kant de Lima, 2014, p. 475).

É no período da formação policial que os futuros policiais passam a se comprometer com a atividade a ser desenvolvida, visto que passam a compartilhar valores, crenças e habilidades uns com os outros, desenvolvendo, desta forma, sua identidade profissional.

A concepção do "ser policial" não só corresponde às características objetivas de seu trabalho, mas também, e com frequência, correlaciona-se ao significado que este trabalho tem para a sociedade e para eles, e isso tem efeitos concretos nas definições que organizam a experiência cotidiana. Nesse sentido, pode-se afirmar que a imagem do policial, que luta contra o crime, tem exercido uma destacada influência no imaginário social e tem influenciado de maneira significativa a identidade profissional desse grupo ocupacional es- pecífico nas sociedades ocidentais contemporâneas. (Poncioni, 2014, p. 505).

É certo dizer que a formação compartilhada possibilita a criação de uma cultura policial, a qual nada mais é que um sistema de representações sociais amplamente difundidas entre seus membros, fundamentadas em "crenças, preconceitos e estereótipos produzidos no interior da própria organização policial sobre as experiências concretas e cotidianas do seu trabalho" (Poncioni, 2014, p. 506).

Ainda que não se possa dizer que a cultura policial é homogênea, tendo em vista a existência de particularidades determinadas pelas distintas realidades sociais em que os agentes estão inseridos, é possível perceber no interior de todas as organizações policiais esse forte discurso de combate ao crime, o qual passa a influenciar a atuação dos agentes, que entram na instituição com anseio de dar um basta nos ilícitos. Para tanto, acabam limitando a possibilidade de efetivar mudanças na política da segurança pública.

Então, ao observar as práticas policiais, constata-se que o exercício do controle social realizado pela polícia é aprendido de maneira informal, visto que os cursos de formação a que os agentes são submetidos não possuem, em sua maioria, disciplinas relacionadas a ele (Kant de Lima, 2013, p. 51).

Aliás, a formação militar conferida aos policiais, ao se ater às obediências legais e hierárquicas, não só os afastou daquelas formações necessárias ao bom desempenho das suas funções, mas também - e principalmente - conferiu à polícia um poder repressivo que até os dias atuais parece não ter sido reduzido.

Com o fim da ditadura militar, o modelo de segurança pública baseado na repressão perdeu seu sentido, mas como não houve mudança substancial na cultura policial - tampouco na própria Constituição -, permanece a mentalidade belicista que constrói inimigos a serem combatidos. (Valente, 2012, p. 205).

Interessante notar que esse processo de militarização da segurança pública desencadeou três consequências facilmente perceptíveis dentro do convívio social, quais sejam: a transformação do controle da criminalidade comum em problema de segurança interna; os problemas relativos à criminalidade passam a orbitar os espaços ocupados pelas agências de controle formal, principalmente pela polícia militar; a polícia passa a adotar estratégias típicas de guerra contra um inimigo comum (Adorno, 1999, p. 133).

E ainda que as suas práticas gerem um temor maior do que a segurança teoricamente assegurada, não é raro vê-los como heróis nacionais quando exercem sua força sobre os mais socialmente perigosos. Afinal, diante de uma sociedade culturalmente ma- 
niqueísta, qualquer indício de neutralização do "poder" dos "maus" é algo a ser celebrado. Este fato corrobora com a ideia socialmente compartilhada de que quanto mais repressor o poder for, melhor.

Essa ideia de que a polícia deve ser heroica e que o confronto mano a mano é que é o modelo ideal do trabalho policial deixa de levar em consideração exatamente aquilo que é a superioridade do Estado: a sua polícia de proteção à população de maneira geral; o que inclui, certamente, policiais e transgressores, mas também transeuntes, inclusive crianças e seus acompanhantes. (Kant de Lima, 2004, p. 75).

Desta forma, tem-se que "a polícia, na verdade, dedica-se cotidianamente a praticar atos que em muito ultrapassam o discreto papel que lhe é determinado pelo arcabouço legal de inspiração liberal sob o qual supostamente vivemos" (Oliveira, 2004, p. 23). Pode-se acrescentar: realizando exatamente aquilo que a sociedade deseja, numa perspectiva da sociedade do controle.

\section{Sociedade do controle: a normalização da juventude}

As relações e construções sociais, no presente trabalho, são analisadas sob a ótica da sociedade de controle. Nesse sentido, as estruturas que envolvem esses adolescentes como alvos de política do Estado e, consequentemente, suas relações com instituições de controle, como a polícia - passam a ser montadas a partir de estruturas que não se restringem somente à sociedade disciplinar, sob uma perspectiva foucaultiana do direcionamento de hierarquias e disciplinas contra o corpo dócil e saudável.

Mais, Passetti (2003) entende que a sociedade disciplinar cede à sociedade de controle, de modo que o interesse não é mais sobre o corpo propriamente dito; os mecanismos de submissão e controle são direcionados a um processo de produção e participação contínua do indivíduo, no qual se criam condições para que cada um sinta-se atuante dentro das diretrizes políticas do governo e responsável pelo seu domínio de assujeitamento, conforme segue:

Na passagem da sociedade disciplinar para a sociedade de controle, anuncia-se um novo acoplamento que não dispensa a internação, explicitando ainda uma permanência das instituições disciplinares, mas agrega a elas controles sofisticados para continuidade da dominação, não mais pelos métodos de introjeção de regras em instituições austeras, mas fazendo de cada um o agente participativo do próprio domínio de assujeitamento. (Augusto, 2009, p. 66-67).

Observe-se que não mais o corpo interessa como instrumento de controle e dominação. A construção de redes que articulam as estruturas da sociedade de controle não são direcionadas diretamente ao corpo como um todo, pois o que interessa são fragmentos ligados à capacidade de produção desses indivíduos (Passeti, 2003, p. 181). Ora, a articulação cada vez mais intensa de um conjunto de redes passa a construir a realidade para quem se encontra inserido nessas estruturas, nas quais a mídia, a internet e demais instrumentos de monitoramento constroem o olhar desses indivíduos sobre eles mesmos (Passeti, 2003).

Nesse sentido, mecanismos presentes na sociedade disciplinar que visavam à maximização do processo de obediência contra o corpo passam a permitir maior participação política desses indivíduos. Segundo Passetti (2003), o cidadão participante é envolvido por uma sensação de liberdade participativa, sentindo-se livre para responder e participar de quaisquer decisões. Entretanto, essa atuação política baseia-se nos instrumentos que sustentam essa rede de dominação, na qual se institui um governo e concepções de segurança apoiados nos discursos midiáticos. Ademais, diz Passetti (2006), "os partidos políticos, o sufrágio universal, ficam reduzidos a elementos do ritual democrático representativo".

Esse talvez seja um dos grandes giros feitos pela sociedade de controle em comparação com a sociedade disciplinar, por mais que não exista uma ruptura entre ambas. A sociedade de controle se consolida a partir de estruturas participativas do indivíduo, com base na tolerância entre os participantes, de modo que se solidifica uma perspectiva plural entre eles. Entretanto, na sociedade disciplinar, a partir de uma perspectiva foucaultiana, o que se observa é um direcionamento do controle não só sobre os corpos, diretamente; mas se exerce um poder coercitivo constantemente intenso sobre os movimentos e posturas, classificados por Foucault (2013, p. 133) como "corpo ativo".

Ademais, a sociedade de controle se estrutura com base em uma perspectiva plural de sociedade. Apesar de não precisar exercer o controle direto sobre o corpo, não abdica da perspectiva de disciplina e castigo, na qual o indivíduo que não corresponde aos anseios de produção vem a ser inserido num processo de exclusão. Nesse sentido, afirma Passetti (2003, p. 31):

A participação contínua dá sentido ao controle contínuo. Todos precisam ser democráticos, numa democracia de antecipação por meio de sondagens. Não se abdica do castigo ou da disciplina, porém agora se investe de outra maneira: o alvo é a rede Estado para o 
corpo são, outro redimensionamento da biopolítica. Mas o estado também não é mais somente investimento sobre o território ou população, é, principalmente, investimento no planeta, no espaço celestial. A biopolítica da população cede lugar, então, a uma ecopolítica planetária.

Dessa forma, no regime de controle se estabelece a constância na produção e participação dos indivíduos, sempre fortalecendo tais estruturas por meio da noção do inacabado, em que o sujeito se insere em uma constante estrutura de cobranças que interessam para a manutenção das estruturas do regime de controle (Passeti, 2003).

Nesse sentido, o Estado mantém suas instituições exercendo suas respectivas funções, a partir das diretrizes dos mecanismos de produção e participação. São as escolas, o Judiciário, o sistema criminal, as instituições psiquiátricas, a polícia e demais instituições de correção de padrões ou de punição que assumem a responsabilidade de manter o inacabado, de estabelecer a participação dos sujeitos da sociedade de controle, até mesmo de garantir a exclusão dos que não se encaixam em suas estruturas.

Aliás, a compaixão e a repressão são valores fundamentais do Estatuto da Criança e do Adolescente (ECA), pois, à medida que a Doutrina da Proteção Integral engendrou a construção universalizada do período da infância, terminou por dirigir a especialização do alvo da Justiça àquele não enquadrado no conceito geral. Neste sentido, três classes da infância se estabeleceram: as crianças que estão incluídas na sociedade e na família (normalizadas); as que estão em perigo, demandando assistência estatal, para as quais devem ser aplicadas as medidas protetoras do artigo 94 do ECA; e aquelas tidas como perigosas, devendo ser submetidas à socioeducação.

Então, à medida que se categorizam tipos de infância, de família, de pessoas, de relacionamento e de responsabilidade, constrói-se o domínio judicial da infância, formando-se perfis, de modo que, se houver alguma criança ou adolescente "fora do lugar ideal" das caracterizações, cabe ao sistema de justiça promover sua alocação. Naturalmente, isso promove a regulação dos estereótipos - bom e mal - com os quais o sistema de justiça está autorizado a dominar a questão da infância (Schuch, 2005).

No presente trabalho, interessa analisar a atuação da polícia dentro das diretrizes da sociedade de controle, em virtude da ampla discricionariedade e da execução de atos de caráter punitivo dos seus agentes na identificação do adolescente suspeito, o que a polícia faz realizando exatamente o que a sociedade participativa demanda dela.

É importante frisar que o processo de identificação do adolescente suspeito passa necessariamente pe- las estruturas plurais da sociedade de controle. Quando se fala em estruturas plurais, deve-se entender isso como a elasticidade dos pressupostos de tolerância, um instrumento de captação de possíveis resistências; ou seja, um arcabouço estrutural constituído por uma combinação de elementos. Nas palavras de Augusto (2009, p. 17), “democracia e cidadania, medicalização e punição combinadas para a normalização do normal".

Nesse sentido, consistem em estruturas que tornam elásticas as formas de disciplina e controle presentes em tal regime. De acordo com Passetti (2003), tais perspectivas criam no regime de controle a ideia de prevenção geral, em que tudo se integra em um constante processo de produção e permite a tolerância de mecanismos violentos contra quem não participa. Assim, diz Passetti (2003, p. 258, grifo nosso):

A rigidez da fronteira de outrora passa a ser substituída pela noção de fronteira elástica; o manifesto foi tomado pelo latente: tudo deve parecer estar em mudança. É a era da metamorfose propriamente dita. A sociedade de controle potencializa a prevenção geral. Faz crer que a humanidade caminha para a paz perpétua, o federalismo planetário, a irmandade feral, o respeito pelas múltiplas culturas por meio do relativismo, o cosmopolitismo como alvo, a fraternidade como estilo de vida. Porém, paradoxalmente, mais uma vez, daí também se anunciam os fascismos.

Essa noção de prevenção geral direciona uma série de mecanismos contra indivíduos que por algum motivo venham a fugir das diretrizes impostas pelo regime de controle, seja por não atenderem às expectativas dos mecanismos de produção e participação a eles direcionados, seja pela própria necessidade do sistema de controle de manter sujeitos seletivamente excluídos.

Como foi visto nas abordagens teóricas desses itens: à luz da criminologia crítica, supõe-se a existência de um processo de criminalização que depende do grau de reação social, e à luz da sociologia criminal, a sociedade do controle demanda uma padronização do jovem aos arquétipos culturais vigentes para a manutenção da ordem social, cabendo à polícia, como primeiro órgão de combate à criminalidade, manter esse status social. Porém, estando ela inserida numa determinada cultura inquisitorial, termina por atuar com base em ilegalidades.

Desse modo, o que se tem como hipótese é que a polícia não faz um trabalho de investigação do fato ocorrido, mas de confirmação de que o adolescente é infrator, ocasião em que a instituição ratifica a sua importância social. Porém, para a verificação dessa hipótese, é preciso se debruçar sobre a ação policial. 


\section{Metodologia de investigação: um olhar sobre a Gerência de Polícia da cidade do Recife}

Nesta pesquisa, a abordagem da realidade visa compreender o funcionamento do sistema infracional, no âmbito da polícia, para a verificação da realidade do funcionamento do sistema de justiça juvenil. Neste sentido, a orientação teórica foi imprescindível, porque baliza a pesquisa para evitar meras descrições de um fenômeno de uma cultura, com afirmações de um tipo popularesco, estilo jornalístico (Becker, 1993, p 40). Assim, a interpretação dos dados será realizada à luz dos marcos teóricos já apontados.

O método utilizado para a realização da pesquisa foi o da observação não participante, que permitiu a compatibilização com a praxe adotada pelos agentes policiais, que não admitiam qualquer tipo de interferência no momento de formalização do flagrante - sendo tal informação repassada diversas vezes, com os anseios da pesquisadora de estar presente neste procedimento.

Tendo como objeto o fenômeno antropológico, a presente pesquisa não poderia se desvirtuar dessa abordagem, razão pela qual houve a preocupação do estudo do diferente, de presenciar algo que se mostre tão incomum e estranho que só possa ser vislumbrado enquanto uma roupagem do "outro" (Rodrigues, 2010, p. 306).

Deste modo, a indicação de que o pesquisador deve se manter afastado do objeto pesquisado, com o intuito de não comprometer a parcialidade, foi um objetivo almejado em todo o transcurso da pesquisa, pois a observação etnográfica tem como importância fundamental possibilitar reflexões sobre as condições em que se produz o conhecimento antropológico e social. Em termos práticos, implica a observação do contexto enquanto fator de interferência na dinâmica social, ou, no caso em análise, no discurso dos atores do sistema penal. O fundamento principal da etnografia está, então, situado na busca pela percepção das particularidades, deixando de lado a esfera das universalizações e generalizações (Peirano, 1995).

Ocorre que, apesar das abordagens qualitativas implicarem um aprofundamento no jogo de papéis, elas demandam esforços pessoais do pesquisador, especialmente porque cabe a este encontrar, por meio da pesquisa sociológica, o essencial do real, cujo cotidiano anula as rotinas comportamentais (Lalanda, 1998).

Inicialmente, na construção da pesquisa, esta interferência subjetiva surgiu como um incômodo, dada a necessária objetividade, tão cara às pesquisas sociológicas. No entanto, a tranquilidade veio em um segun- do momento, com o acalanto sincero da necessidade do reconhecimento do anthropological blues, apresentado por DaMatta (1978, p. 30-33):

Aspectos interpretativos do ofício de etnólogo, sempre prontos a emergir em todo relacionamento humano [...] é o sentimento e a emoção e tudo indica que tal intrusão da subjetividade e da carga afetiva que vem com ela é um dado sistemático da situação e que aparentemente pode implicar, dentro da rotina intelectualizada, na indicação da falta de objetividade [...].

Explica o autor que a vivência entre dois mundos e duas culturas diferentes, ainda que dentro do mesmo espaço geográfico, implica, no campo das rotinas, estranhar o familiar, permitir que aspectos (mesmo que familiares) tornem-se extraordinários, pois não se pode perder de vista de que o familiar não é necessariamente conhecido em seus significados. Muito pelo contrário, é sobre esse objeto que se debruça para conhecê-lo.

O que se quer refletir é que, mesmo que se evite, todos têm sua cota de estereótipos, cujo estoque é formado pelas experiências sociais do indivíduo, o que ainda é acrescido, no caso do pesquisador, de outras tantas imagens correntes de seus círculos profissionais. Nesse sentido, diz (Becker, 2007, p. 33): “Nós cientistas sociais, sempre atribuímos implícita ou explicitamente, um ponto de vista, uma perspectivas e motivos às pessoas cujas ações analisamos".

E a partir da construção dos mapas e hierarquias individuais, seus elementos funcionam como normas sociais que geram conflitos com outros pontos de vista, de pessoas diversas, demandando, assim, uma permanente negociação da realidade a partir dos atores que apresentam interesses divergentes. A ciência social se desenvolve exatamente nesta conjuntura, tendo "toda uma dimensão iconoclasta voltada para o exame crítico e dessacralizador da sociedade" (Velho, 1978, p. 45).

Trata-se, enfim, da tentativa de identificação de mecanismos conscientes e inconscientes que sustentam e dão continuidade às relações sociais. Uma postura que demanda o estranhamento do pesquisador, mesmo diante aquilo que lhe é mais familiar, propondo-se este, sempre, a relativizar seus próprios mapas mentais, num processo de reflexão sistemática. Não cabe, deste modo, ao pesquisador classificar e rotular os indivíduos a partir de suas normas de socialização.

Mas, se estas vedações são dogmas para o pesquisador, elas são instrumentos de investigação quando se procura compreender o outro, posto que este não está consciente (e nem precisa) desta realidade. Muito pelo contrário, é assim que ele age na sua interação cultural. Como diz Lalanda (1998, p. 882):

O sociólogo com os atores não anula o distanciamento que a ciência exige. Antes transforma a recolha de informação numa experiência que "humaniza" a 
própria investigação, ou seja, proporciona ao investigador a possibilidade de "ver por dentro", tomando uma dupla posição de observação: a de investigador e a do próprio actor.

As questões dos subjetivismos metodológicos aliviaram a preocupação inicial dos pesquisadores, pois restou claro que o processo de conhecimento da vida social implica um grau de subjetividade, e a realidade, seja ela familiar ou exótica, é filtrada pelo ponto de vista do observador. Assim, a objetividade é relativizada, devendo sempre ser exercitada a capacidade intelectual de perceber por diferentes versões as interpretações acerca de um fato.

Neste sentido, é inevitável tomar partido na pesquisa (Becker, 1997), pois a interpretação dos dados da realidade depende dos valores, da inclinação política e ideológica do pesquisador - índices de QI, por exemplo, podem ser interpretados como herança genética (inalterável) ou como algo restrito a uma cultura (alterável), não podendo ser usado para comparar populações diferentes (Becker, 2009).

É neste sentido que a pesquisa pode dar ênfase, por exemplo, a grupos superiores, numa relação organizada, como funcionários de uma instituição (deixando evidente a hierarquia de credibilidade, ao reforçar suas responsabilidades, em que as falas negam seus fracassos); ou a grupos subordinados, os quais, desprovidos de organização e da responsabilidade do funcionamento do serviço, não precisam mentir, como fazem aqueles, e ao ter seu ponto de vista exaltado, terminam por lançar dúvidas sobre a linha oficial, questionando a hierarquia de credibilidade.

$\mathrm{Na}$ escolha de uma ou outra abordagem, pelos mesmos motivos, hábias. Numa pergunta corriqueira, isto pode ser identificado: por que os jovens são tão problemáticos para os adultos? Ou (na mesma importância), por que os adultos dão tanto trabalho à juventude?

Contudo, se de um lado as subjetividades são reais na pesquisa, por outro, é necessário satisfazer algumas exigências em termos de objetividade. Como explica Luciano Oliveira (1988, p. 125), existe uma neutralidade latu sensu e outra stricto sensu, em que "a primeira, aplicada ao conjunto da atividade de investigação científica, é impossível, mas que a segunda, aplicada a um dos momentos em que se divide essa atividade, é indispensável". O importante é a objetividade possível, que consiste no método - controle factual -, há de se seguir rigorosamente as técnicas deste.
Neste sentido, se é verdade que os fatos são feitos, também é verdade que esta "feitura deve obedecer as regras que sejam aceitas pelo pensamento lógico, como são as da representatividade amostral, das inferências estatísticas, etc." (Oliveira, 1988, p. 126). Ou seja, escolhido o método, tem-se que usá-lo corretamente. Esta é a objetividade possível.

O procedimento de pesquisa se deu em experiências obtidas no âmbito da Gerência de Polícia da Criança e do Adolescente (GPCA) da cidade de Recife, Pernambuco, por etapas, tendo sido realizadas diversas formalidades indispensáveis à presença naquela delegacia. Em primeiro momento, o núcleo administrativo deixou algumas impressões acerca do adolescente em conflito com a lei - expressão esta que foi substituída pela palavra "menor" no mesmo instante em que foi pronunciada.

Entre essas impressões, estava a de que os "menores" eram irrecuperáveis e isto era "fruto da própria legislação que, por ser fraca" permitia isso. Explicaram que a área de flagrante funcionava apenas no plantão, havendo uma rotatividade entre 4 equipes - cada uma sob o comando de uma autoridade policial distinta -, que trabalhavam 24 horas. Além dessas equipes, havia uma delegada que cuidava dos assuntos considerados "importantes". Posteriormente, foi explicado que ela não atua em casos de flagrantes, mas apenas quando há queixas ou diligências a serem realizadas

A pesquisa teve seu início no dia 26 de fevereiro de 2015 e se estendeu até 27 de março do mesmo ano, período em que foram presenciados 15 flagrantes, registrando-se às vezes mais de um flagrante por dia. ${ }^{4}$ Nos dias em que não houve qualquer movimentação, a pesquisadora esteve presente no cartório, sala em que é realizado o procedimento, e sempre que apresentava o ofício com a justificativa para sua pesquisa, os policiais deixavam claro que essa formalidade era uma besteira. Não olharam nada, apesar de o delegado ter pedido para eles analisarem o conteúdo do documento.

\section{Análise de dados: "Polícia de gente e polícia de moleque!"s}

Independentemente de que os agentes façam parte da polícia militar ou da civil, tendo em vista que as circunstâncias a que estes dois grupos estão submetidos são muito semelhantes, há um significa-

4. A realização da pesquisa se deu obedecendo à seguinte rotina: como regra geral, a pesquisadora se dirigia à GPCA por volta das 13 horas e saía, aproximadamente, às 17 horas. Nos dias em que não havia nenhum caso, a pesquisa prosseguia até as 17 horas e 30 minutos. Em dias bastante excepcionais, durava das 15 horas às 19 horas.

5. A partir presente tópico, visando conservar a pessoalidade e o protagonismo dos registros etnográficos, em alguns momentos do texto o plural, adotado até o presente momento, será substituído pela primeira pessoa do singular. 
tivo ponto em comum entre eles que deve ser considerado. A semelhança a que fazemos referência está pautada na rotatividade dos agentes, podendo esta ser verificada em maior ou menor grau.

No que diz respeito aos agentes da polícia militar que conduzem os adolescentes até a delegacia, a rotatividade observada é muito maior, tendo em vista a quantidade de batalhões existentes na Região Metropolitana do Recife. Uma vez ou outra é possível encontrar o mesmo policial do dia ou da semana anterior, mas esta situação foi ficando cada vez mais rara ao longo das semanas.

Em relação à polícia civil, seus agentes encontravam-se em situação semelhante aos da polícia militar, pelo seguinte motivo: como atuavam em plantões, não era o mesmo grupo que estava em serviço todos os dias, de modo que pudemos ter contato com vários agentes.

O ponto a ser analisado consiste no discurso proferido por estes servidores, que, através das suas frases, demonstravam, de forma autoritária, qual o papel a ser desempenhado tanto pelos adolescentes apreendidos como por eles, no âmbito da repartição.

\section{"Adolescente é para encarcerar mesmo!"}

O sentimento de muitos - senão de todos - que estão ali é evidenciado pela frase que um escrivão proferiu, ao comentar a greve da polícia realizada em 2014, em Recife: "Nós somos a última barreira entre o bem e o mal". Essa percepção acaba por propagar, através dos próprios agentes policiais, a ideia de que o adolescente ali presente representa um perigo a ser combatido, de forma a preservar a sociedade não só da conduta que deu causa à sua apreensão, mas também de futuros atos que poderão ocorrer.

Esta ideia pôde ser retratada em duas oportunidades, no transcorrer da pesquisa, quando os escrivães se dirigiram à pesquisadora para falar dos procedimentos adotados quando da chegada do adolescente na GPCA. Em um primeiro momento, houve um questionamento quanto à possibilidade jurídica de o adolescente sair da repartição no mesmo dia da apreensão, sendo apontado que tal prática é muito rara; o que configura uma ilegalidade, ${ }^{6}$ pois "quando o ato não é praticado com violência, o menor não pode ficar na delegacia, mas eles ficam”.
Mais que um autoritarismo dos agentes policiais, que justificam a utilização do seu (abuso de) poder para garantir a ordem pública, tem-se a presunção de que o adolescente praticará outro ato infracional.

Em segundo momento, o discurso veio à tona quando foi dito que os adolescentes, além de serem dirigidos ao IML para realizar exame de corpo e delito, podem ser levados à Unidade de Pronto Atendimento (UPA) antes mesmo de irem para a GPCA, para "depois não podem dizer que a gente bateu neles aqui, imagina a bronca." Aqui há uma preocupação restrita à possível responsabilização atribuída aos agentes da Polícia Civil, não tendo a integridade física dos adolescentes, quando apreendidos, qualquer tipo de importância. A pena informal é essa.

Como se vê, claramente, os fundamentos da cultura policial anteriormente discutida acabam sendo reproduzidos pela instituição. De fato, há uma relevante preocupação, por parte dos agentes, em estabelecer o limite de avanço da criminalidade; porém, apesar da discricionariedade com a qual atuam, visam à manutenção da aparente legalidade, apesar de ela aparentar ser um mero verbete.

\section{$O$ adolescente na delegacia tem um lugar: o da não cidadania}

Com a prática do ato infracional, o adolescente é posto como personagem secundária, pois agora ele é o delinquente. A depender do ato praticado, o estigma poderá ser atribuído em menor ou maior grau, permitindo que seja realizado um juízo de valor, pelos próprios agentes, acerca das reais necessidades por trás dos pedidos dos adolescentes, que podem receber atenção ou não.

Ao contrário do que se possa presumir, esses pedidos são tidos como "regalias", consistentes, por exemplo, em vestir uma peça de roupa distinta da que ele usava no momento da apreensão, a qual é trazida pelos familiares ou pela namorada. ${ }^{7}$ De forma alguma há uma atribuição da condição de sujeito a qualquer adolescente; mas, sim, uma diminuição do grau de delinquência que lhe é atribuído.

Dos casos verificados, foi possível constatar que os apreendidos por tráfico de drogas tinham seus pedidos atendidos. Apesar da crença de que estes não agiam por necessidade econômica, mas, sim, porque queriam um caminho mais fácil para conseguir di-

6. O Estatuto da Criança e do Adolescente dispõe, em seu artigo 174, sobre a possibilidade de adolescentes serem imediatamente liberados, caso o ato infracional não envolva violência ou grave ameaça, não cabendo à autoridade policial fazer qualquer juízo de valor que fundamente uma atuação em sentido contrário.

7. A questão de gênero é realmente determinante. Somente namoradas aparecem na delegacia quando os adolescentes são apreendidos. O mesmo não se dá com adolescentes do sexo feminino. 
nheiro, há, no âmbito policial, uma banalização desse ato infracional, tendo em vista o grande número de apreensões referentes a ele. Um ou outro que fugia a essa regra tinha o tratamento mais rígido.

Apesar destas variações de tratamento, havia uma certeza: de alguma forma, independentemente do ato infracional praticado, os menores tinham sua condição de sujeitos de direito reduzida. Em determinados momentos, os adolescentes se transformavam em coisa, completamente diferente daqueles indivíduos que protagonizam uma proteção, seja na Constituição Federal, seja no Estatuto da Criança e do Adolescente.

As palavras, quando dirigidas a eles, sempre procuravam lembrar-lhes sua condição de inferioridade. Abaixo, um diálogo entre um policial civil e um policial militar, a respeito de um jovem apreendido quando tentava arremessar para o presídio Aníbal Bruno duas supostas "bananas" de explosivos, demonstra essa conclusão:

Escrivão: Não sei se isso é explosivo mesmo.

Policial: Bota no xadrez com o menor dentro pra ver se explode.

(...)

Escrivão: Oxe, esse boy tava internado e saiu em novembro.

Policial: A gente tá em março, ele passou muito tempo na rua já. Não aprendeu, né, boy?

Escrivão: A solução pra esse é a morte

Em outro momento, a consequência advinda do estigma de delinquente foi percebida quando da comunicação aos pais do adolescente, para que estes se dirigissem à GPCA. Ainda que a comunicação aos pais esteja prevista no artigo 107 do ECA, o escrivão afirmou que "só avisam aos pais porque há uma portaria". Se, neste momento, preferiu-se utilizar uma fala velada para retratar a desnecessidade de chamar alguém para saber de alguém sem importância, em outro momento este discurso mostrou-se mais claro, revelando, até mesmo, a percepção de que o adolescente é uma coisa. Neste dia, o escrivão, ao ser questionado por um colega sobre se tinha ligado para os pais do jovem apreendido, disse: "Quem quer saber disso? Isso tem família não".

Ademais, as algemas são artifícios materiais constantemente utilizados para lembrar aos adolescentes onde eles estavam e quem eles eram ali. Não era difícil encontrar algum deles com algemas apertadas, ora utilizadas com os braços para trás, ora para frente. $\mathrm{O}$ desconforto era evidente, independentemente da posição. Certo dia, pudemos ver as marcas que as algemas deixavam nos braços deles.

Entretanto, a condição de criminoso do adolescente não era relembrada só para ele, mas também para terceiros que estivessem em sua volta. No caso, nós, que, quando estávamos sentados nas cadeiras em que eles costumam ficar quando chegam na GPCA, fomos alertados: "Aí não é lugar pra você sentar, só para os menor [sic]". Este aviso foi confirmado dias depois, quando um policial, ao me ver sentada nessas mesmas cadeiras, determinou que o adolescente sentasse no chão, ainda que eu tivesse dado espaço para que ele se sentasse em alguma das cadeiras restantes.

O fundamento do Estatuto da Criança e do Adolescente se mostra tão descompassado com a realidade instituída que, quando o delegado - apenas um, dos quatro que davam plantão - chamava o adolescente para conversar, sua atitude era tida como desnecessária pelos escrivães, que, ao zombar a autoridade policial, diziam que ele não era "nada prático".

É a comprovação da utilização da delegacia como ambiente eminentemente repressivo, o que é próprio da perspectiva institucional, como já visto. Ambiente idealizado para reprimir condutas e tratar aqueles que ali adentram como merecem: sem o mínimo de dignidade. Não bastasse isso, os policiais, tentando se eximir de qualquer culpa quanto ao tratamento conferido aos adolescentes, utilizavam o seguinte discurso: "Tratamos bem, desde que eles tratem bem também".

Ainda que esta frase deixe transparecer que o adolescente conduz o tom da conversa - que ele é responsável não só pelos seus atos, mas também pelos dos outros -, não foi difícil perceber que a conversa fluía, principalmente, de acordo com o humor e a disposição dos agentes, ainda que estes justificassem tais medidas com um possível desrespeito do menor, o que quase nunca era observado.

Ao adolescente não é permitido decidir nada. $\mathrm{O}$ mínimo de voz que ele ganhava representava uma afronta à sociedade, que, constantemente, era tida como vítima dos seus atos, os quais, por sua vez, sob o olhar dos agentes policiais, não ensejavam qualquer tipo de responsabilização real.

Indo mais além, a marginalização acentuada do adolescente no âmbito da própria GPCA lhe era devida logo nos procedimentos que fazem parte da sua recepção no estabelecimento. Não raramente as "boas-vindas" a que o adolescente está submetido, quando da apreensão em flagrante, dão-se em forma de intimidação acerca da continuidade de uma vida tida como criminosa.

No diário de campo, foi possível observar algumas situações onde este "conselho" se mostrou presente, sendo proferido pelos agentes tanto da polícia civil como da polícia militar. In verbis:

(i) Vão te matar na rua. Isso se antes o policial não estourar teu ouvido. Eles fazem isso e tu nunca mais vai ouvir direito na vida. 
(ii) Tivesse sorte, boy, se outro te pega, tu tava quebrado. Eu não faço isso. Se a lei não dá jeito, eu que não vou dar, mas nem todos pensam assim. Te liga.

(iii) Se fossem outros PMs, vocês não estariam aqui. A gente viu, sentiu as pernas tremendo, sentiu a emoção e pegamos vocês. Pensem na vida, mermão. Tá pensando que é brincadeira, é? Estuda. A gente também não era nada, mas estudou e passou num concurso. O caminho do crime é fácil, mas se a gente tiver por perto vai ser pedregoso. Na próxima, tu vai.

(iv) Perdeu o celular, boy. Dá graças a Deus que perdesse só isso. Na próxima vez, tu perde a vida.

(v) Tá pensando que o caminho de Deus é fácil, é? Não é fácil não, se liga. Vai pra igreja. Ou continua assim que a gente te pega de novo e aí é cadeia.

(vi) Deram azar, bem feito. Trabalha, porra.

(vii) Ou sai dessa vida ou morre nela. Insiste nessa vida, vai. Pra mim, tanto faz, tu é só mais um. Agora, na próxima, tu vai é pro COTEL e lá não são 45 dias não, o tratamento é outro. São 2, 3 anos, até alguém comer teu oití (...).

Como se vê, há uma neutralização da subjetividade do adolescente, com a finalidade de satisfazer os anseios do sistema de justiça criminal. Ademais, a atuação de ofício de um órgão policial pressupõe a existência de uma situação em que existam sujeitos suspeitos o suficiente para despertar a atividade da polícia. Uma estratégia corrobora a outra.

Assim, ter-se-ão as polícias de gente e de moleque, que se concentram em um único órgão. Esta divisão na denominação advém de uma atuação plural sobre indivíduos que praticam um ilícito penal. Pode-se dizer, mesmo, que, ao considerar sobre quem esses controles são exercidos, há um quê de patrimonialismo na base que fundamenta a instituição policial:

A longa tradição (e experiência) de uma polícia de gente, dócil em relação aos privilégios de classe e status em sua atividade rotineira de imposição da ordem, e de uma polícia de moleque, nunca hesitante em usar o chicote no trabalho de domesticação das rebeldias individuais e coletivas das classes baixas traduziu o problema do controle social coletivo (...). (Paixão; Beato, 1997, p. 233).

Com o aumento da criminalidade cada vez mais evidenciado pelos meios de comunicação, esta dicotomia presente no órgão policial passa a ser cada vez mais escancarada. Isto porque, em tempos em que o sistema de justiça criminal se mostra desacreditado pela população, a reação para tal provocação vem em forma de resultados, estando estes quase sempre vinculados a uma violência institucionalizada.

Como a própria seletividade deixa à mostra, esta violência não recai sobre todos. Existem alguns bodes expiatórios que passam a ser alvos, estando estes representados pelos pobres, negros e indivíduos fora da faixa escolar, quando não alfabetizados. Atuando sobre os grupos socialmente marginalizados - aqueles que determinadas classes temem -, a polícia de moleque, mais que a polícia de gente, passa a ser exercida - e veiculada - de forma mais incisiva, de forma a dar uma resposta aos que demandam por sua intervenção.

Esta intervenção não raramente está associada a situações tidas como emergenciais por determinadas classes, que, ao sentirem seus interesses ameaçados, pedem por uma maior atuação policial. Esta resposta vem, não só por uma repressão supostamente baseada na legalidade, mas, quase sempre, também acaba vindo em forma de resoluções extralegais de agressões.

O certo é que, por meio de provocações sociais ou não, a seletividade - assim como a violência institucionalizada - passa a ser um aspecto intrínseco aos órgãos policiais, sendo observada durante ou em um momento anterior ao procedimento "oficial" a ser adotado para que haja um controle social.

Ou seja, a polícia atua no sentido de realizar a segurança pública como sua missão, e assim o faz acima de todas as garantidas legais, pois o que importa é detectar o infrator, sem que o fato praticado por ele seja relevante, em termos de investigação; o que importa é que o menor exista, para que a polícia, satisfatoriamente, realize seu mister.

\section{A normalização dentro da sociedade disciplinar}

Suspeitos, disciplina e controle são elementos que permeiam as estruturas sociais de uma sociedade inserida em relações de fluxo cada vez mais dependentes dos olhares desconfiados entre as pessoas. Um sistema formal e informal de controle que, além de cobrar participação e produção do indivíduo, submete-o a um processo constante de exclusão quando encontra nele condutas de desvio e resistência às diretrizes de controle. Nesse sentido, o regime de controle articula as estruturas de suas instituições, como a polícia, a partir de um modus operandi de repressão, desconfiança e punição, no qual tais mecanismos são direcionados a quem, de certa forma, foge a tais perspectivas.

Impende-se ressaltar, entretanto, que o objetivo da presente análise não foi explicar diretamente mecanismos de criminalização desses adolescentes, mas 
apenas traçar observações acerca da identificação desses indivíduos como suspeitos, dentro das diretrizes da sociedade de controle.

Ademais, em virtude de limitações metodológicas, a própria análise de identificação de pontos comuns que direcionam uma possível atuação da polícia, bem como a construção da figura do adolescente, é restrita, visto que não abarca uma perspectiva conjuntural desses indivíduos; omite, por exemplo, a relação deles com o meio ao qual estão inseridos - ou seja, a construção de laços entre esses indivíduos e o local onde vivem -, e como tal fato pode vir a contribuir na identificação desse adolescente, pela polícia, como suspeito.

Nesse sentido, a presente análise se limita à mecânica de identificação, a partir da polícia, da figura do adolescente suspeito com base em processos de exclusão marcados pelas diretrizes da sociedade de controle. O que se percebeu é realmente o exercício de um processo de controle de adolescentes que não se enquadram em perfis de juventude socialmente aceitos.

Uma breve análise dos dados disponibilizados pelo Núcleo de Juízo de Execuções das Medidas Socioeducativas em Meio Aberto (NEMA) aponta quem são esses adolescentes que passaram pela atuação da polícia, mesmo que em um momento anterior ao da execução das medidas socioeducativas, no período de agosto a dezembro de 2014. Nesse sentido, basta observar a faixa etária, o grau de escolaridade e a situação ocupacional desses adolescentes para identificar quem são esses indivíduos que, perante a polícia, constituem a figura do suspeito.

Tabela 1 - Perfil dos adolescentes que em um momento prévio sofreram abordagem policial

\begin{tabular}{|l|l|}
\hline Faixa etária & $\begin{array}{l}69 \%: 15 \text { a } 17 \text { anos } \\
31 \%: 18 \text { a } 21 \text { anos }\end{array}$ \\
\hline \multirow{3}{*}{ Escolaridade } & $\begin{array}{l}\text { 53\%: Ensino fundamental I incompleto } \\
45 \%: \text { Ensino fundamental II incompleto } \\
\text { 2\%: Não alfabetizado }\end{array}$ \\
\hline $\begin{array}{l}\text { Situação } \\
\text { ocupacional }\end{array}$ & $\begin{array}{l}\text { 25\%: Sem trabalho } \\
4 \%: \text { Trabalho informal }\end{array}$ \\
\hline
\end{tabular}

Fonte: Dados disponibilizados pelo Núcleo de Juízo de Execuções de Medidas Socioeducativas em Meio Aberto (NEMA).

A partir de uma simples observação, comparando-se a faixa etária e o grau de escolaridade desses adolescentes, é latente uma ausência de correspondência entre a idade desses indivíduos e o grau de escolaridade "normal" nessa faixa etária, visto que são adolescentes com pelo menos 15 anos que não concluíram o ensino fundamental I - ou seja, não cursaram sequer a $5 .^{\text {a }}$ série (sexto ano) -, o que previamente nos alerta para uma relação no mínimo problemática com as instituições escolares.

Ademais, o baixo grau de escolaridade também nos permite deduzir qual a classe econômica a que tais indivíduos pertencem, visto que adolescentes pertencentes a classes sociais mais privilegiadas economicamente em geral possuem um grau de escolaridade condizente com sua respectiva faixa etária. Nesse sentido, evidencia-se quem são esses sujeitos que já se encontravam inseridos em um processo de exclusão econômica, fato que apenas confirma parte da seletividade do sistema penal e do processo de exclusão dos regimes de controle.

Outrossim, são indivíduos que, no que se refere às atividades ocupacionais, em sua maioria vivenciam uma situação de desemprego, conforme mostram os dados segundo os quais mais de $70 \%$ do universo analisado encontram-se excluídos do mercado de trabalho e apenas 3\% desses adolescentes possuem algum vínculo formal de emprego. É o que se observa ao se relacionar esse conjunto de dados, na tentativa de identificar pontos comuns que caracterizam esses adolescentes, os quais, antes do início da execução de medida socioeducativa, passaram pela identificação, pela polícia, como suspeitos.

Alguns pontos nos chamam a atenção. Primeiramente, são adolescentes que, por algum motivo, possuem uma relação conflituosa com o sistema educacional. Seja com a escola como instituição, seja com a metodologia pedagógica adotada pelo sistema de educação. São sujeitos que não se encaixam nas estruturas ali postas, muitas vezes por falta de estímulo em se manter na instituição; talvez pela ausência de identificação, ou pela própria falta de interesse da instituição em manter esses adolescentes no sistema educacional.

Esse processo de exclusão prossegue com seu rito e execução dos mecanismos de controle quando se observa a situação ocupacional na qual esses indivíduos de baixa renda estão enquadrados - mais de $70 \%$ encontram-se sem qualquer perspectiva de construção de renda por meio de atividades laborais lícitas. Um processo de exclusão que possivelmente ajudará a despertar mecanismos de criminalização direcionados contra aqueles adolescentes. Ora, temos uma soma de fatores que podem contribuir para possíveis condutas identificadas como criminosas e, consequentemente, direcionar um processo de suspeição das atividades policiais contra aqueles indivíduos. Nesse sentido, diz Passetti (2008, p. 11, grifo nosso):

A escola, em parceria com a comunidade, que surpreendentemente estigmatiza o indisciplinado como sangue ruim, delinquente, marginal, vagabundo, fol- 
gado, entre tantos outros adjetivos pejorativos, abre a via para a sua inclusão no trabalho ilegal, disponibilizando-os como serviçais, falcões, papagaios e sicários.

Nesse sentido, em que pese a possível particularidade de cada caso, não abarcada na presente análise, a identificação do adolescente suspeito pela polícia é direcionada a indivíduos que já se encontram inseridos em um processo de exclusão, principalmente por não se encaixarem nos interesses participativos e produtivos da sociedade de controle. Assim, uma série de mecanismos de disciplinamento é direcionada a esses sujeitos, na qual instrumentos de produção e disciplina determinam e legitimam o olhar desconfiado da sociedade e do Estado sobre eles. Indivíduos que passam por um processo de assujeitamento "pelo que ele não deve ser ou pelo que deve deixar de ser, que se diz e fabrica o que é um indivíduo normal" (Augusto, 2009, p. 70).

A criação do suspeito, mesmo que indiretamente, assume uma relação intrínseca com o processo de exclusão desses indivíduos. Não se está aqui dizendo que o fato de esses adolescentes possuírem condutas desviantes quanto às diretrizes institucionais (em relação à escola, por exemplo) é o que os tornam necessariamente suspeitos, pelo olhar do Estado.

\section{Considerações finais: a construção social do adolescente suspeito}

Como visto, uma série de fatores está presente na construção social do adolescente suspeito, não sendo possível desassociá-lo, pelo menos em um momento inicial, do processo de exclusão em que está inserido. É certo que outros processos se inserem nessa construção, como rótulos e consequências secundárias que contribuem, de forma negativa, no direcionamento da mecânica do Estado contra "aquilo que o adolescente deve deixar de ser". Conforme afirma Tannenbaum, citado por Werneck (2014, p. 19-20):

O processo de produção de um criminoso é [...] de etiquetagem, definição, identificação, segregação, descrição, ênfase, conscientização e condução ao inconsciente, torna-se uma forma de estimular, sugerir, enfatizar e evocar as próprias ameaças de que reclama. [...] A pessoa se torna a coisa que é descrita como sendo.

Nesse sentido, a polícia - como instituição de controle estatal e repressão de atos e indivíduos que venham a fugir do padrão de produção e participação estabelecido pela sociedade - submete-se à mecânica das políticas de exclusão, escamoteadas com pressu- postos de prevenção contra condutas indesejáveis, de modo que tais pressupostos são instrumentalizados em políticas públicas de segurança e, possivelmente, irão resultar no ápice da segregação desses indivíduos, com sua inserção no sistema carcerário. Assim, diz Augusto (2009, p. 80):

No que diz respeito à polícia como instituição estatal, que se ocupa da saúde da população como conjunto vivo que compõe o corpo biológico do Estado, se ela passa a ser identificada, com esse nome, apenas como instituição repressiva para conter revoltas internas contra o Estado, o sentido das políticas de Estado como forma de garantir a saúde da população receberá o nome de política social, o que nos leva a aproximar as maneiras de investimentos estatais no que se chama, sob a dominância liberal, de política pública, compondo uma ação policial do Estado sobre a população como estratégia, também, de conter revoltas, ampliar o esplendor do Estado e extrair obediências.

A polícia funciona, conforme exposto acima, como instrumento de garantia da "saúde" da população, saúde como imposição de processos de integração do indivíduo aos mecanismos de participação e produção da sociedade de controle, seja com base na perspectiva de prevenção geral, seja através de mecanismos de repressão contra adolescentes que não interessam ao regime de controle. Isto é, o adolescente em conflito com a lei, como sujeito pertencente a determinado grupo social, passa a ser alvo de um controle, advindo das agências criminais ou das próprias instituições sociais, antes mesmo de praticar um ato infracional.

Invisíveis nas relações interpessoais, os indivíduos pertencentes a esse grupo são postos em evidência pelas agências de controle, que os têm como alvo da sua atuação. São aqueles que, apesar de virem a praticar um ato infracional - e por isso são denominados adolescentes em conflito com a lei -, estão sob a mira de todo um sistema que espera pelo momento em que eles, finalmente, poderão ser apreendidos. Nesse momento, eles serão reduzidos a um dado estatístico que confirma o discurso falacioso proferido por uma determinada classe e acolhido pelo Estado, através dos seus agentes.

Integrados no sistema criminal na posição de réus, os adolescentes passam a receber um tratamento tão ou mais repressivo que aquele conferido aos maiores de idade, caindo por terra as determinações presentes no ECA. Esta situação, por vezes, se dá pelo fato de os agentes acharem que as medidas estabelecidas pelo documento legal são insuficientes. $\mathrm{Na}$ visão deles, a própria legislação, por ser branda demais, contribui para a inserção destes indivíduos em carreiras criminosas. 
$\mathrm{Na}$ pesquisa realizada na GPCA, tanto os policiais civis como os militares manifestaram essa insatisfação em relação à legislação vigente. Para eles, se a lei é conivente com os menores, eles não são. E, arbitrariamente, passam a agir contrariamente à lei. De forma mais explícita: agem no âmbito da ilegalidade, sendo amparados para tal tanto pela população como pelo Estado, que reage aos comandos desta; aliás, na sociedade disciplinar, é isso que a população busca - a participação e o controle das subjetividades.

Desta forma, não é difícil observar, nos corredores da GPCA um tratamento destinado aos adolescentes, por parte dos policiais, que em nada se parece com a proteção integral presente no ECA. Se para a polícia ele é apenas um delinquente - pois é isso que o termo menor, com seu eufemismo, deixa à mostra -, para o governo ele será apenas um dado a ser veiculado por seus órgãos oficiais, e, para os jornais, apenas uma notícia na página policial.

Como se vê, o sistema de controle a que estes jovens são submetidos tem a mesma essência do sistema criminal, não havendo qualquer cisão entre eles. Isto é, a medida dita educativa conferida aos adolescentes tem a mesma carga de punição e responsabilização que a pena retributiva destinada ao adulto (Nicodemos, 2006, p. 65-66).

E tal repressão não se dá apenas em instância de execução, visto que eles, assim como os adultos, estão sujeitos a todo o processo de criminalização evidenciado pela teoria da reação social, cujas variáveis são exatamente as da sociedade do controle, a qual expressa valores que cada membro da população, de alguma forma, compartilha.

No final, confirma-se a hipótese apresentada, de que a polícia, para consolidar sua atuação e sua necessidade social, trata o adolescente como menor, independentemente do ato infracional praticado por ele, Assim, é possível observar que a punição aplicada pelos agentes vai além da compreensão que todos têm acerca do que é legalmente correto ou errado. Há, entre eles, uma ética policial que deve ser respeitada pela sociedade (Kant de Lima, 2004, p. 13).

Sim, porque, cabendo à polícia selecionar os suspeitos para prevenir e reprimir a criminalidade - e não havendo relações de confiança nem com a sociedade, nem com o Judiciário, mas estando próxima ao crime -, entende a polícia que somente ela teria experiência com o crime; algo como "a polícia tem que fazer justiça com as próprias mãos porque o Judiciário é incompetente para fazê-la" (Kant de Lima, 1989, p. 8).

O que termina por reduzir a concepção hierárquica da sociedade: acima da polícia está o Judiciário e abaixo dela, o criminoso, contra quem tudo está autorizado. Ou seja, enquanto a lei é "pública e universal, conhecida obrigatoriamente por todos, a todos igualmente se aplicando, a ética policial é privada e particularista, como os métodos inquisitoriais da polícia”. (Kant de Lima, 1989 p, 13)

\section{Referências}

ADORNO, Sérgio. Insegurança versus direitos humanos. Tempo Social, Universidade de São Paulo, São Paulo, v. 11, n. 2, p. 129-153, out. 1999.

AUGUStO, Acácio. Política e polícia: medidas de contenção de liberdade: modulações de encarceramento contra os jovens na sociedade de controle. 2009. Dissertação (Mestrado) - Pontifícia Universidade Católica de São Paulo, São Paulo, 2009.

BARATTA, Alessandro. Criminologia crítica e crítica do Direito Penal. Introdução à sociologia do Direito Penal. Rio de Janeiro: Revan, 2002.BECKER, Howard. De que lado estamos? Uma teoria da ação coletiva. Rio de Janeiro: Zahar, 1977.

BECKER, Howard. Métodos de pesquisa em Ciências Sociais. Tradução: Marco Estevão e Renato Aguiar. São Paulo: Hucitec, 1993.

BECKER, Howard. Outsiders: estudos da sociologia do desvio. Rio de Janeiro: Zahar, 2003.

BECKER, Howard. Segredos e truques da pesquisa. Rio de Janeiro: Zahar, 2007.
BECKER, Howard. Falando da sociedade. Ensaios sobre as diferentes maneiras de representar o social. Rio de Janeiro: Zahar, 2009.

COSTA, Ana Paula Motta. Os adolescentes e seus direitos fundamentais. Porto Alegre: Livraria do Advogado, 2012. DAMATTA, Roberto. As raízes da violência no Brasil: reflexões de um antropólogo social. In: PAOLI, Maria Célia et. al. A violência brasileira. Brasília: Brasiliense, 1982.

DAMATTA, Roberto. O ofício de etnólogo, ou como ter "anthropological blues". In: NUNES, E. O. (Org.). A aventura sociológica. Rio de Janeiro: Zahar, 1978.

FELTRAN, Gabriel de Santis. Diário intensivo a questão do adolescente em conflito com a lei em contexto. Revista Brasileira Adolescência e Conflitualidade, n. 4, p. 1-44, 2011.

KANT DE LIMA, Roberto. Éticas e práticas na segurança pública e na justiça criminal. In: LIMA, Renato Sérgio de; RATTON, José Luiz; AZEVEDO, Rodrigo Ghiringhelli de. Crime, Polícia e Justiça no Brasil. 
São Paulo: Contexto, 2014.

KANT DE LIMA, Roberto. Antropologia, Direito e Segurança Pública: uma combinação heterodoxa. Cuadernos de Antropología Social, n. 37, 2013.

KANT DE LIMA, Roberto. Direitos civis e Direitos Humanos: uma tradição judiciária pré-republicana? São Paulo Perspectiva, São Paulo , v. 18, n. 1, p. 4959, mar. 2004

KANT DE LIMA, Roberto. Polícia, Justiça e Sociedade no Brasil: uma abordagem comparativa dos modelos de administração e conflitos no espaço público. Revista de Sociologia e Politica, Curitiba, n. 13, p. 23-38, 1999.

KANT DE LIMA, Roberto. Polícia e exclusão da cultura judiciária. Tempo Social, Universidade de São Paulo, São Paulo, v. 9, n. 1, p. 169-183, maio 1997.

KANT DE LIMA, Roberto. Cultura jurídica e práticas policiais. A tradição inquisitorial. Revista Brasileira de Ciências Sociais, Rio de Janeiro, v. 4, n.10, jun. 1989.

LALANDA, Piedade. Sobre a metodologia qualitativa na pesquisa sociológica. Análise Social, Lisboa, v. 33, n. 148, p. 871-883, 1998.

MACHADO, Érica Babini L. do A. Medida socioeducativa de internação: do discurso (eufemista) à prática judicial (perversa) e à execução (mortificadora): um estudo do continuum punitivo sobre adolescentes do sexo feminino em conflito com a lei na cidade do Recife. 2014. Tese (Doutorado em Direito) - Universidade Federal de Pernambuco, Pernambuco, 2014.

MALLART, Fábio. Cadeias dominadas. A Fundação Casa, suas dinâmicas e trajetórias de jovens internos. São Paulo: Terceiro Nome, 2014.

MAGNANI, João Guilherme Cantor. De perto e de dentro: notas para uma etnografia urbana. Revista Brasileira de Ciências Sociais, São Paulo, v. 17, n. 49, 2002. NICODEMOS, Carlos; SILVA, Antônio F. do A.; PAULA, Paulo A. G. Natureza do sistema de responsabilidade do adolescente autor de ato infracional. In: ILANUD; ABMP; SEDH; UNFPA (Org.). Justiça, adolescente e ato infracional. São Paulo: Ilanud, 2006.

OLIVEIRA, Luciano. Neutros \& Neutros. Humanidades, Brasília, n. 19, p. 122-127, 1988.

OLIVEIRA, Luciano. Sua excelência, o comissário e outros ensaios da sociologia jurídica. Rio de Janeiro: Letra Legal Editora, 2004.

PAIXÃO, Antônio Luiz; BEATO FILHO, Claudio C. Crimes, vítimas e policiais. Tempo Social, Universidade de São Paulo, São Paulo, v. 9, n. 1, p. 233-248, maio 1997.

PAIXÃO, Antônio Luiz; BEATO FILHO, Claudio C. Humanidades, Brasília, n. 19, p. 122-127, 1988.

PASSETTI, Edson. Anarquismos e sociedade de controle. São Paulo: Cortez, 2003.

PASSETTI, Edson; ACÁCIO, Augusto. Violentados: crianças, adolescentes e Justiça. São Paulo: Imaginário, 1999.

PASSETTI, Edson; ACÁCIO, Augusto. Educação $e$ anarquia: abolir a escola. São Paulo, 2008. Disponível em: <http://www.nu-sol.org/agora/pdf/passettiaugusto. pdf $>$. Acesso em: 2 mar. 2015.

PASSETTI, Edson; ACÁCIO, Augusto. Educação e liberdade. Pontifícia Universidade Católica de São Paulo, São Paulo, 2006. Disponível em: <http://www.nu-sol. org/artigos/ArtigosView.php?id=2>. Acesso em: 3 set. 2015.

PEIRANO, Mariza. A favor da etnografia. Rio de Janeiro: Relume-Dumará, 1995.

PONCIONI, Paula. Identidade profissional policial. In: LIMA, Renato Sérgio de; RATTON, José Luiz; AZEVEDO, Rodrigo Ghiringhelli de. Crime, Polícia e Justiça no Brasil. São Paulo: Contexto, 2014.

RODRIGUES, Guilherme T. M. Antropologia e Direito: a justiça como possibilidade antropológica. 2010. $406 \mathrm{f}$. Tese (Doutorado em Ciências Sociais) - Universidade Estadual Paulista de Ciências Sociais, São Paulo, 2010.

ROSA, Alexandre Morais da; LOPES, Ana Cristina Brito. Introdução crítica ao ato infracional. Princípios e garantias constitucionais. 2 ed. Rio de Janeiro: Lumen Juris, 2011.

SCHUCH, Patrice. Práticas de Justiça: uma etnografia do "campo de atuação ao adolescente infrator" no Rio Grande do Sul, depois do Estatuto da Criança e do Adolescente. 2005. Tese (Doutorado em Antropologia) - Universidade Federal do Rio Grande do Sul, Porto Alegre, 2005.

SCHUR, Edwin M. Labeling Deviant Behavior. Its sociological implications. New York: Harper \& Row Publishers, 1971.

VALENTE, Júlia Leite. "Polícia militar" é um oximoro: a militarização da segurança pública no Brasil. Revista do Laboratório de Estudos da Violência da Unesp, São Paulo, n. 10, dez. 2012.

VELHO, Gilberto. Observando o familiar. In: NUNES, E. O. (Org.). A aventura sociológica. Rio de Janeiro: Zahar, 1978.

WERNECK, Alexandre. Teoria da rotulação. In: LIMA, Renato Sérgio de; RATTON, José Luiz; AZEVEDO, Rodrigo Ghiringhelli de (Org.). Crime, Polícia, e Justiça no Brasil. São Paulo: Contexto, 2014.

ZAFFARONI, E. R. Criminología: aproximación desde una márgen. Colômbia: Editorial Temis, 2003.

ZALUAR, Alba. Adolescência e criminalidade. In: RIZZINI, Irene. A criança no Brasil hoje: desafio para o terceiro milênio. Rio de Janeiro: Editora Universitária Santa Úrsula, 1993.

ZALUAR, Alba. Integração perversa: pobreza e tráfico de drogas. Rio de Janeiro: Editora FGV, 2004. 


\title{
Cop culture and the suspect youth - the normalization in Police of Recife
}

\begin{abstract}
The paper presents the social representation of the police in the time of the prison of the youth in crime. The authors used the critical criminology and criminal sociology to guide theoretically the research and methodological they have done ethnography observation. The hypothesis guided by those theoretical frames is that the policies doesn't respect legality and are arbitrary in their activity, because they are pressured to provide public security and in the same time, they are disbelieved social and juridical. Between these ambiguity, considering the criminalization is result of a social labeling and these institution have to reaffirm your social importance, the police has to perform what society demands - normal pattern of youth. In this way, the figure of suspect adolescent is built.
\end{abstract}

Keywords: Police, youth in crime, suspect and normalization.

\section{Cultura policial adolescente sospechoso - normalización en la Gestión}

\section{Policial en Recife}

\section{Resumen}

El artículo analiza las representaciones sociales de la policía en el momento del registro del auto de prisión in fraganti de adolescentes en conflicto con la ley. Se obtuvieron las respuestas a través de la observación etnográfica, a partir de la problematización levantada por marcos teóricos de la criminología crítica y de la sociología criminal, en que se tuvo como hipótesis la idea de que, si la criminalización es un proceso de rotulación y si las policías, en general, son instituciones desacreditadas jurídica y socialmente, , aunque de ellas la población demanda seguridad pública, otra conclusión no podría ser extraída a no ser la de que los agentes de esas instituciones no respetan la legalidad y actúan de manera arbitraria, en el sentido de ejecutar los modelos de normalidad que la sociedad establece y, consecuentemente, reafirmar su importancia social. En este sentido estaría orientada la construcción social del adolescente sospechoso.

Palabras clave: policía, adolescentes en conflicto con la ley, sospechoso y normalización.

Data de recebimento do artigo: 05/ 2016

Data de aprovação do artigo: 11/2016 